\title{
NOMOPHOBIA AMONG SLOVAK ADOLESCENTS
}

\author{
Katarina Holla - Viktoria Nagyova
}

doi: 10.18355/PG.2020.9.1.1

\begin{abstract}
This study addresses nomophobia as a growing fear in today's world - the fear of being out of cellphone contact. Our goal was to detect and map nomophobia among the adolescents. The research sample consisted of 404 adolescents aged $15-20$. In terms of research methods, we used Yildrima and Correia's (2015) Nomophobia Questionnaire (NMP-Q).

The questionnaire dimensionality includes four inter-correlated factors. Nomophobia has been identified in the following cases - when the adolescents could not perform an immediate communication and once they lost the access to information. This phobia was further detected at several levels as moderate ( $49 \%$ of adolescents), mild (38\% of adolescents) and severe (12\% of adolescents). Our findings are deemed to be important and necessary in providing support for the reasonable cellphone use at schools and related institutions.
\end{abstract}

\section{Key words}

nomophobia, adolescents, Nomophobia Questionnaire, confirmatory factor analysis (CFA)

\section{Theoretical background of nomophobia}

Technological development, the rise of social networks and the Internet connection make us spend a lot of time online. In fact, the current generation of children and adolescents cannot even imagine their lives without cellphones, electronic devices and Internet access. The real social issue of a modern world is the heavy use of cellphones and the addiction to mobile devices. Such excessive and often uncontrollable use of these devices is also related to the increased ownership of cellphones by Generation Z and Alpha. The problem strikes once the adolescents lose their access to cellphones and Internet connection. As a result, they often feel lost in this world. Both cellphone addiction and fear of being out of cellphone contact (nomophobia) are considered modern-day issues that are being addressed by many pedagogical, psychological, sociological, medical and other experts. Nomophobia is a form of behavioral smartphone addiction. It refers to the anxiety which evolves after losing a mobile network connection or smartphone access. Foreign experts who deal with nomophobia include Yildirim and Correia, Gerzin et al., Argumosa-Villar et al., Khilnani et al., Choliz, etc. The name itself derives from a longer expression "no mobile phobia". The term "nomophobia" was first used in 2008 by Yildirim and Correia (2015). These researchers define the issue as a situational phobia related to agoraphobia (a fear of falling sick and being unable to receive the first aid or immediate assistance). In such situations, the individuals happen 
to be at places with insufficient network coverage, unavailable Wi-Fi connection or dead cellphone battery.

Nomophobia has been discussed and analyzed in several foreign countries. Australian research, for example, involved 292 respondents aged $16-24$ and focused on the incidence of nomophobia in different age groups. It turned out that the age had no impact on the incidence of nomophobia (Argumosa-Villar et al., 2017). In Germany, the research sample consisted of 104 students. Severe nomophobia was detected for less than $3 \%$ of students, while the mild form of nomophobia affected almost $40 \%$ of students (Davie, N., Hilber, T., 2017). Another research in India on 331 respondents (58\% of men and $42 \%$ of women) showed that the incidence of nomophobia was significantly higher for people who frequently used and checked their cellphones on a daily basis. Almost 3/4 (73\%) of respondents express how time-consuming it might be to use cellphones and that it also affects the other activities during the day (Khilnani et al., 2019).

People who suffer from nomophobia (nomophobes) are not able to put their cellphones aside for a longer amount of time. Nomophobes tend to always check their phones and do not turn them off - not even at night. As the addiction is getting more serious, the communication with the outside world is being reduced to online conversation via cellphones and applications.

We can often see that these symptoms are already being experienced by the current generation of children and adolescents. Symptoms of nomophobia include: feelings of deprivation, loneliness or despair after being separated from cellphone or unable to use it due to dead battery, checking the cellphone and thinking about it all the time, and fear of losing, breaking or not being able to use the cellphone (Gezgin et al., 2017).

There are multiple foreign-research instruments to detect nomophobia. We will describe two instruments that have been used to a great extent nowadays. The first instrument is Yildirim and Correia's (2015) Nomophobia Questionnaire NMP-Q that was created and validated in the USA. The second questionnaire used for nomophobia detection is Choliz's (2012) The Test of Mobile Phones Dependence (TMD) that was created and standardized in Spain. We opted for the NMP-Q questionnaire to meet the needs of our research and detect nomophobia among Slovak adolescents.

\section{Methodological establishment of the present issue}

Research goal: We aimed at detecting and mapping nomophobia among Slovak adolescents aged $15-20$. Although the research was rather descriptive, we wanted to take full advantage of the research instrument. It was, therefore, necessary to further investigate both dimensionality and internal consistency of its items.

Research instrument: We worked with the NMP-Q questionnaire that included 20 items. The total score of these items could reach $20-140$ points and be divided into four levels as:

1. The absence of nomophobia - The individuals' use of smartphones is healthy and the separation from such devices does not raise any difficulties. 
2. Mild nomophobia - The individuals experience mild distress in the absence of their smartphones or Wi-Fi connection and feel a bit anxious.

3. Moderate nomophobia - The individuals feel a strong attachment to their smartphones and need to check the news and information most of the time. The anxiety comes when people perform non-smartphone related activities.

4. Severe nomophobia - The individuals check their smartphones all the time. It is the first thing they do in the morning and the last one when they go to sleep. Smartphones are dominant in their everyday activities (Gregoire, 2015).

Statistical methods: The NMP-Q questionnaire dimensionality was evaluated through confirmatory factor analysis (CFA). The CFA analysis uses different criteria to assess the quality of particular research model. Such criteria include the root mean square error of approximation (RMSEA) value that should be less than 0.05 to prove the model appropriate. As for CFI (comparative fit index) and TLI (Tucker-Lewis index), the values should be at least 0.95 to consider the model adequate (Hu \& Bentler, 1999). The fourth index refers to SRMR (standardized root mean square residual). The model is suitable if the value is less than 0.08 (Hu \& Bentler, 1999). Total internal consistency of NMP-Q items, as well as the questionnaire dimensionality, was estimated with Cronbach's Alpha $(\alpha)$.

Research sample: The research involved 404 high school students aged 15 -

20 who came from all parts of Slovak Republic. The sample consisted of $55 \%$ of female respondents and $45 \%$ of male respondents.

\section{Empirical findings}

When analyzing NMP-Q questionnaire in the Slovak background, we began with the investigation of research instrument dimensionality. Confirmatory factor analysis (CFA) helped us compare three different models. First singlefactor model (M1) suggested that nomophobia could be considered unidimensional construct. Second four-factor orthogonal model (M2) was used by the questionnaire authors Yildirim and Correia (2015). Third, and the last, four-factor model (M3) recognizes correlation possibilities among its factors.

\section{First model (MI)}

In the M1 model, the values reached for each criterion are as follows:

$\mathrm{x}^{2}(170)=511.41 ; \mathrm{p}<0.001 ; \mathrm{CFI}=0.741 ; \mathrm{TLI}=0.710 ; \mathrm{RMSEA}=0.098$ with $90 \%$ confidence interval: [0.092; 0.105]; $\mathrm{SRMR}=0.084$.

Second model (M2)

$\mathrm{x}^{2}(170)=1192.45 ; \mathrm{p}<0.001 ; \mathrm{CFI}=0.828 ; \mathrm{TLI}=0.797 ; \mathrm{RMSEA}=0.105$ with 90\% confidence interval: [0.099; 0.111]; SRMR $=0.340$.

The M2 model is generally more reliable as the first M1 model. However, it is still not suitable enough due to unsatisfactory results.

Third model (M3)

The M3 is a four-factor non-orthogonal model. Compared to M1 and M2 models, the M3 option showed the best compliance with the required data: 
$\mathrm{x}^{2}(164)=473.42 ; \mathrm{p}<0.001 ; \mathrm{CFI}=0.958 ; \mathrm{TLI}=0.951 ; \mathrm{RMSEA}=0.051$ with $90 \%$ confidence interval: [0.045; 0.058]; SRMR $=0.053$. The likelihood-ratio test (LR test) result confirmed that the M3 model was more appropriate than the M2 model as $\mathrm{x}^{2}(6)=719.03 ; \mathrm{p}<0.001$.

Image 1 CFA structural graph for the M3 model

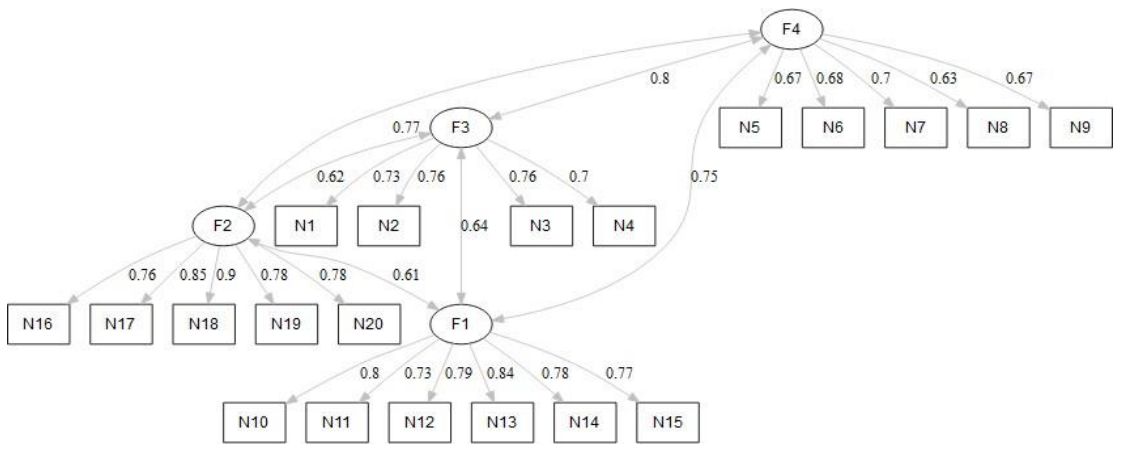

N1 - N20 items measure the F1 - F4 latent nomophobia constructs. Bidirectional arrows represent how these four latent variables correlate.

Items N1 - N20 show quite strong (>0.50) and statistically significant $(\mathrm{p}<0.001)$ positive correlation with the associated factor. Cronbach's Alpha of each item reached high values for given factors (first factor's $\alpha=0.90$, second factor's $\alpha=0.91$, third factor's $\alpha=0.82$ and fourth factor's $\alpha=0.80$ ). Factors F1 - F4 are rather interesting as they show a strong positiveness and have statistically significant correlations ( $\mathrm{p}<0.001)$, ranging from $0.61(\mathrm{~F} 1 \&$ F2) to 0.80 (F3 \& F4).

Yildirim and Correia (2015), the questionnaire authors, as well as the experts like Ma and Liu (2018) claim that it refers to the four-dimensional construct. Our research further confirms that the construct has indeed four dimensions and inter-correlated factors. Factors of this four-dimensional construct include: not being able to perform an immediate communication (items: N10 - N15), losing online connectedness (items: N16 - N20), not being able to access information (items: $\mathrm{N} 1$ - N4), and giving up convenience (items: N5 N9). It seems that Slovak version of NMP-Q questionnaire is suitable for the assessment of nomophobic behaviors among the adolescents.

Table 1 shows descriptive statistics of N1 - N20 items. The data in each of these items suggest that all respondents strongly agreed on the following statements: I would not want to feel uncomfortable without constant access to information through my smartphone ( $\mathrm{N} 11 ; \mathrm{M}=4.29 ; \mathrm{SD}=2.02 ; \mathrm{MED}=4), I$ would be annoyed if I could not look up the information on my smartphone when I wanted to do so ( $\mathrm{N} 2 ; \mathrm{M}=4.13 ; \mathrm{SD}=1.94 ; \mathrm{MED}=4)$, I would feel anxious if I could not instantly communicate with my family and/or friends (N13; $\mathrm{M}=4.10 ; \mathrm{SD}=2.04 ; \mathrm{MED}=4)$. On the other hand, they strongly disagreed on the following statement: I would feel anxious because I could not check my email messages $(\mathrm{N} 19 ; \mathrm{M}=2.32 ; \mathrm{SD}=1.86 ; \mathrm{MED}=1)$. 
Table 1 Descriptive statistics of the NMP-Q questionnaire items

\begin{tabular}{|c|c|c|c|c|c|c|}
\hline Item & $\mathrm{M}$ & SE & SD & Med & Kurtosis & Skew \\
\hline N1 & 3.95 & 0.09 & 1.90 & 4.0 & -1.04 & 0.04 \\
\hline $\mathrm{N} 2$ & 4.13 & 0.10 & 1.94 & 4.0 & -1.11 & -0.08 \\
\hline N3 & 3.93 & 0.11 & 2.14 & 4.0 & -1.41 & 0.13 \\
\hline N4 & 4.04 & 0.10 & 1.98 & 4.0 & -1.17 & 0.01 \\
\hline N5 & 3.41 & 0.11 & 2.18 & 3.0 & -1.28 & 0.40 \\
\hline N6 & 3.04 & 0.11 & 2.13 & 2.0 & -0.86 & 0.71 \\
\hline N7 & 3.86 & 0.11 & 2.13 & 4.0 & -1.33 & 0.15 \\
\hline N8 & 2.91 & 0.10 & 1.95 & 2.0 & -0.69 & 0.71 \\
\hline N9 & 3.30 & 0.10 & 1.98 & 3.0 & -1.04 & 0.45 \\
\hline N10 & 3.88 & 0.10 & 2.05 & 4.0 & -1.26 & 0.06 \\
\hline N11 & 4.29 & 0.10 & 2.02 & 4.0 & -1.23 & -0.18 \\
\hline $\mathrm{N} 12$ & 3.57 & 0.10 & 2.03 & 3.0 & -1.17 & 0.29 \\
\hline N13 & 4.10 & 0.10 & 2.04 & 4.0 & -1.22 & -0.04 \\
\hline N14 & 3.65 & 0.10 & 1.96 & 4.0 & -1.12 & 0.16 \\
\hline N15 & 3.73 & 0.10 & 2.02 & 4.0 & -1.21 & 0.18 \\
\hline N16 & 2.78 & 0.10 & 2.00 & 2.0 & -0.45 & 0.90 \\
\hline N17 & 2.43 & 0.09 & 1.85 & 1.5 & 0.27 & 1.16 \\
\hline N18 & 2.67 & 0.09 & 1.90 & 2.0 & -0.39 & 0.90 \\
\hline N19 & 2.32 & 0.09 & 1.86 & 1.0 & 0.44 & 1.28 \\
\hline $\mathrm{N} 20$ & 2.84 & 0.10 & 2.01 & 2.0 & -0.76 & 0.75 \\
\hline
\end{tabular}

deviation,

Med-median, Kurtosis, Skew)

Based on the above-mentioned data, we can state that nomophobic behavior of research participants showed as their inability of the immediate communication. Students were therefore unable to communicate and benefit from the related services in their cellphones which is typical for this level of nomophobia. Nomophobia was further demonstrated as sufferers' inability to access information. Characteristic symptoms include distress and fear of not being able to search information via cellphone and its services.

Considering the F1 - F4 factors, we sought to map the incidence of nomophobia among people of different gender and age with the MIMIC model. The MIMIC model results (see Table 2) indicate that the relation between participants' gender and F1, F3, F4 nomophobia dimensions is statistically insignificant ( $>0.05)$. As such, the average level of F1, F3 and F4 nomophobia dimensions does not seem to be distinct for boys and girls. The average level of $\mathrm{F} 1$ and $\mathrm{F} 4$ dimensions is higher for boys $(\mathrm{B}>0)$, while the average level of $\mathrm{F} 3$ dimension is higher for girls $(\mathrm{B}=-0.055)$. The only 
significant gender difference $(B=0.429 ; \mathrm{p}=0.022)$ was observed for $\mathrm{F} 2$ dimension where the average latent variable values were higher for boys.

Table 2 Standardized and non-standardized regression coefficients in the MIMIC model

\begin{tabular}{|c|c|c|c|c|c|}
\hline $\begin{array}{c}\text { Latent } \\
\text { variable }\end{array}$ & Covariate & B & beta & SE & $\mathrm{p}$ \\
\hline \multirow{2}{*}{$\mathrm{F} 1$} & Gender & 0.154 & 0.047 & 0.172 & 0.371 \\
\hline & Age & -0.059 & -0.058 & 0.055 & 0.281 \\
\hline \multirow{2}{*}{$\mathrm{F} 2$} & Gender & 0.429 & 0.124 & 0.186 & 0.022 \\
\hline & Age & -0.001 & -0.001 & 0.057 & 0.981 \\
\hline \multirow{2}{*}{ F3 } & Gender & -0.055 & -0.020 & 0.154 & 0.718 \\
\hline & Age & 0.002 & 0.003 & 0.050 & 0.965 \\
\hline \multirow{2}{*}{$\mathrm{F} 4$} & Gender & 0.171 & 0.060 & 0.159 & 0.283 \\
\hline & Age & -0.010 & -0.012 & 0.051 & 0.840 \\
\hline
\end{tabular}

After the overall examination, all nomophobia dimensions reported statistically insignificant relation to respondents' gender and age. This assertion thus implies that neither age nor gender affects the incidence of nomophobia.

In the following part, we focus on mapping the individual nomophobic levels among Slovak adolescents. Apart from four dimensions/factors, there are also four nomophobic levels: none, mild, moderate and severe nomophobia.

Table 3 Regional nomophobia incidence among Slovak adolescents

\begin{tabular}{lcccc}
\multirow{2}{*}{\multicolumn{1}{c}{ Region }} & \multicolumn{3}{c}{ Nomophobia } \\
\cline { 2 - 5 } \cline { 2 - 5 } & none & mild & moderate & severe \\
\hline Banská Bystrica & $1(2 \%)$ & $22(35 \%)$ & $28(45 \%)$ & $11(18 \%)$ \\
Bratislava & $0(0 \%)$ & $22(43 \%)$ & $23(45 \%)$ & $6(12 \%)$ \\
Košice & $0(0 \%)$ & $16(36 \%)$ & $25(56 \%)$ & $4(9 \%)$ \\
Nitra & $0(0 \%)$ & $17(29 \%)$ & $30(52 \%)$ & $11(19 \%)$ \\
Prešov & $0(0 \%)$ & $13(33 \%)$ & $23(58 \%)$ & $4(10 \%)$ \\
Trenčín & $0(0 \%)$ & $20(38 \%)$ & $30(57 \%)$ & $3(6 \%)$ \\
Trnava & $2(4 \%)$ & $17(37 \%)$ & $20(43 \%)$ & $7(15 \%)$ \\
Žilina & $1(2 \%)$ & $25(51 \%)$ & $20(41 \%)$ & $3(6 \%)$ \\
\hline Slovakia (in total) & $4(1 \%)$ & $152(38 \%)$ & $199(49 \%)$ & $49(12 \%)$ \\
\hline
\end{tabular}

Image 2 Nomophobia histogram

As we can see in the table and histogram above, the moderate level of nomophobia seems to be prevalent. The Kruskal-Wallis test results show little statistically significant difference of the adolescent nomophobia levels for individual Slovak regions $\left(\mathrm{x}^{2}(7)=9.51 ; \mathrm{p}=0.218\right)$. It turned out that moderate nomophobia (49\%) was the most frequent form within our research sample. It is followed by mild (38\%) and severe (12\%) nomophobia. The absence of adolescent nomophobia did not exceed $1 \%$. 


\section{Nomophobia}

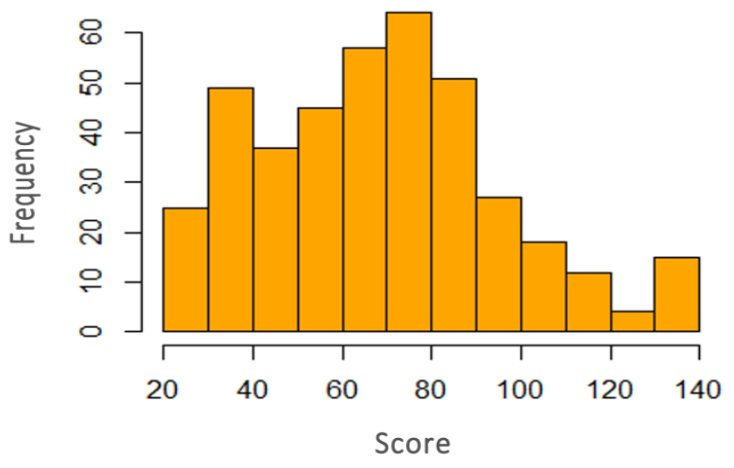

\section{Discussion and conclusions}

The phenomenon of nomophobia is rather new in our digital/virtual society. As a part of our research, we verified the $N M P-Q$ questionnaire dimensionality in order to assess nomophobic behavior. Close examination revealed that this construct consisted of four dimensions with strong positive correlations. With regard to Yildirim and Correia's (2015) four-factor structure, Gregoire's (2015) levels of nomophobia, as well as participants' region, age and gender, we further investigated the incidence of the "no mobile phone phobia". Moderate nomophobia (49\%) turned out to be the most prevalent form of this disorder, followed by mild (38\%) and severe (12\%) nomophobia. The absence of adolescent nomophobia reached only $1 \%$. Such alarming number suggests that almost all respondents suffer from at least one form of nomophobia. The investigation of gender - nomophobia relation proved that the dimensional level was not that different between boys and girls. Although compliant with the results provided by Argumosa-Villar et al. (2017), the results obtained in Choliz's (2012), Ozdimer and Arslan's (2018) research showed that girls suffered from nomophobia more often than boys.

Nomophobia came when students could not perform immediate communication and lost the access to information. These situations occurred either when people could not communicate via forgotten/dead smartphone or due to other reasons, such as ongoing classes, school clubs or practices. Nomophobes then experienced distress and fear of being unable to answer their calls and receive information. Our research reveals that the adolescents might feel uncomfortable (with no constant access to news and information), angry (with no possibilities to search information) and anxious (with no chance to contact their family and/or friends via smartphones). It is highly important to detect the incidence of the adolescent nomophobia. This disorder results from the extensive and long-term smartphone usage which has a negative impact on peoples' health. Hence, the proper interventions are needed to support reasonable cellphone usage, especially in case of 
adolescent students who bring their electronic devices to schools and related institutions. Nomophobia might cause distraction and thus lead to lower academic performance during classes. As prevention, we should teach the adolescents the right way to use their smartphones, i.e. when it is the right time to put them away and the time to reach for them again. One of the increasing demands calls for the establishment of such academic and extracurricular activities that would engage the adolescents in real world rather than in cyberspace. Academic institutions are responsible for limiting the use of cellphones instead of prohibiting them as no one can escape the technological revolution. It is very important for teachers to plan the curriculum that would offer their students various tips on how to search and work with information. This enhances the development of critical thinking. Student's use of smartphones can be limited by various education activities performed during individual classes, as well as events organized within the class or at whole-school level, e.g. The International Safer Internet Day (February 8). Safer Internet Day is dedicated to protection of personal data, especially on social network sites. To support prevention, different types of online threats, e.g. sexting, cyberbullying, cyber grooming, nomophobia and FoMO could be discussed on various seminars and workshops.

On days like The World Day WITHOUT Internet (January 29) and The World Day Without Mobile Phones (February 6), we believe that the incentive Internet and mobile abstinence, as well as important "face to face" communication, should take place at schools and related institutions.

It is essential to make children and adolescents realize that the online acquaintances might not be our real friends. People must think twice before sharing their private messages, photos or even intimate information online or with another person. Such prevention might be also applied to free time activities, after school care for children, school clubs or even summer camps for kids.

Cellphone usage is related not only to nomophobia and Internet addiction disorder, but also to the other online threats, such as various cyberbullying forms that affect Slovak children and adolescents, as well (Dulovics, Kamenska, 2017; Niklova, Makuchova, 2018). The connections between nomophobia factors/levels and individual sexting forms (self- and peer-sexting, sexting that results from the excessive watching of sexual/sexually explicit music videos) are certainly worth investigating in further details. The achieved results indicate that institutions working with vulnerable generation of children and adolescents would do well to come up with new or expand the existing programs that can enhance students' digital literacy. This would be particularly helpful in case of excessive at-risk usage of cellphones or other electronic devices.

\section{Bibliographic references}

ARGUMOSA-VILLAR, L., ET AL. 2017. Exploratory investigation of theoretical predictors of nomophobia using the Mobile Phone Involvement Questionnaire (MPIQ). Journal of Adolescence. 2017, vol. 56, no. 17, ISSN 0140-1971. 
BHAVANA, S. - VIJAYALAKSHMI, V. 2019. Psychological impacts of smartphone on college students -nomophobia (No-mobile-phone phobia). In International Journal of Recent Technology and Engineering, vol. 8, no. 4, pp. 2559-2564.

DAVIE, N. - HILBER, T. 2017. Nomophobia: Is Smartfone Addiction a genuine risk for mobile learning? 13th International Conference Mobile Learning. 2017 ISBN 978-989-8533-61-6, pp. 100 - 104.

DULOVICS, M. - KAMENSKA, J. 2017. Analysis of Cyber-Bullying Forms by Aggressors in Elementary and Secondary Schools. The New Educational Review, vol. 49. no. 3, pp. $126-137$.

GEZGIN, D. M., et al. 2017. Nomophobia Prevalence among Pre-service Teachers: A case of Trakya university. Trakya Journal Of Education. 2017, vol. 7, no. 1, ISSN 2146-071X.

RODRÍGUEZ-GARCÍA, A. M. - BELMONTE, J. L. - MORENOGUERRERO, A. J. 2020. Nomophobia: An individual's growing fear of being without a smartphone a systematic literature review. In International Journal of Environmental Research and Public Health, vol. 17, no. 2, p.,580.

GREGOIRE, C. 2015. This scientific test will tell you how addicted you are to yours smartphone. Huffpost. [online]. 2015. vol. 5, no. 18. [cited 27-22019]. Online: https://www.huffingtonpost.com/2015/05/18/nomophobiasmartphone- sep_n_7266468.html?guccounter=1.

HU, L. - BENTLER, P. M. 1998. Fit indices in covariance structure modeling: Sensitivity to underparameterized model misspecification. Psychological Methods. 1998, vol. 3, no. 4 ISSN 1939-1463.

CHOLIZ, M. 2012. Mobile-phone addiction in adolescence: The Test of Phone Dependence (TMD). In PROGRESS IN HEALTH SCIENCES. 2012, vol. 3, no. 1, ISSN 2083-1617.

KHILNANI, K. A. et al. 2019. Prevalence of nomophobia and factors associated with it: a cross-sectional study. Journal of Research in Medical Sciences. 2019, vol. 7, no. 2 ISSN 2320-6012.

KLINE, P. 2000. The Handbook of psychological testing. vol. 2 London: Routledge, 2000. ISBN 0-415-21158-1.

MA, J. - LIU, CH. 2018. Evaluation of the factor structure of the Chinese version of the nomophobia questionnaire. Current psychology (New Brunswick, N.J.) DOI: 10.1007/s12144-018-0071-9.

NIKLOVA, M. - MAKUCHOVA, J. 2018. Forms of Cyber-bullying from the Aspect of Cyber-victims - Elementary and Secondary School Pupils. The New Educational Review, vol. 51, no. 1, DOI: 10.15804/tner.2018.51.1.12, ISSN $1732-6729$ pp. $150-161$.

OZDIMER, H. O. - ARSLAN, H. N. 2018. The Dark side of communication: Nomophobia. 1.Uluslararasi halkla ilişkiler ve reklamcilik kongresi. Antalya. E-ISBN: 978-975-2475-73-1.

YILDIRIM, C. - CORREIA, A. P. 2015. Exploring the dimensions of nomophobia: Development and validationof a self-reported questionnaire. Computer in Human Behavior. [online]. 2015, vol. 15, no. 49. [27-12-2018]. Available

online: 
https://www.researchgate.net/publication/273705474_Exploring_the_dimensi ons_of_nomo phobia_Development_and_validation_of_a_selfreported_questionnaire. ISSN 0747-5632.

doc. PaedDr. Katarína Hollá, PhD.

Department of Pedagogy

Faculty of Education

Constantine the Philosopher University

Dražovská cesta 4, 94901 Nitra

Slovakia 